\title{
Dell Hymes and the Ethnography of Communication
}

Barbara Johnstone and William M. Marcellino

Rhetoric Program, Department of English

Carnegie Mellon University

Pittsburgh PA 152123 USA

Corresponding author: bj4@andrew.cmu.edu

Dell Hymes' formative role in the ethnography of communication, ethnopoetics and educational ethnography alone merit him biographic attention. In addition, though, tracing out Dell Hymes' career arc offers a window on the birth and development of sociolinguistics as a whole. The particular cluster of early influences on Hymes - Franz Boaz, Edward Sapir, Roman Jakobson and Kenneth Burke - as well as Hymes' resulting resistance to Chomskyan linguistics, are representative of the sources of impetus for sociolinguistics in general. Hymes had an abiding personal and scholarly interest in American Indians in all their linguistic and cultural diversity. He argued for a widened scope for linguistics which started with diversity rather than in a search for the universal. In particular, he wanted linguists to pay attention to the poetic, aesthetic, reflexive aspects of discourse through which cultural knowledge is circulated. His interest in diversity has always been linked with a concern for the sources and consequences of inequality, and much of his work has taken place in the context of educational research. In Hymes' interests, we can see sociolinguistics' recurring concerns. If we want to understand how sociolinguistics grew out of linguistics, understanding Dell Hymes' life and career is a good place to start.

\section{Life and Intellectual Biography}

Hymes was born in Portland, Oregon in 1927. He grew up there, attending Reed College as an undergraduate, and began graduate work in anthropology at Indiana University in 1950, eventually receiving a doctorate instead in linguisticsm in 1955, with minors in anthropology and folklore. This constellation of interests would stay with Hymes throughout his career. C. F. Voegelin, Hymes' dissertation advisor at Indiana, described Hymes as 'a literary critic and minor poet who surprised us at Indiana when shifting from very general cultural interests to linguistics' (Murray, 1998: 100). For Hymes, though, these interests were naturally allied, allowing him to explore 'the use of language, oral narrative and poetry, the history of anthropology and linguistics, Native Americans, theology' (Hymes, n.d.). While at Indiana, Hymes began his association with Roman Jakobson, whose 'crucial contribution was to introduce a 'functionalist' perspective and to do so in a way that suggested an empirical, manageable way of dealing with speech functions' (Hymes, 1975: 364), quoted in (Murray, 1998: 100). That functionalist concern with how humans actually use language would steer Hymes' work and presages sociolinguistics' concern for contextualized language use. 
From Indiana, Hymes became an assistant professor of linguistics at Harvard University, but was denied tenure in 1960. Hymes was then offered a position at Berkeley, in both anthropology and linguistics. This was a fortuitous appointment. While other American linguistics departments were beginning to focus increasingly on Transformational-Generative grammar and other abstract models of linguistic competence, Berkeley's department remained focused on descriptive work on non-English languages, and the 'social and cultural determinants of language' (Murray, 1998: 101). Murray characterizes Berkeley as being split between an old guard of linguists interested in fieldwork, resulting in descriptions of languages, and a younger generation interested in developing theoretical frameworks for studying language use. That younger generation, which included founding sociolinguists like Hymes, Erving Goffman, John Gumperz and Susan Ervin-Tripp, grounded their work in the Sapirian tradition, but expanded their concerns with language beyond description .

Although their concern for the functions of language in social life represented a break from structural linguistics, there was clearly collegial respect between the emerging sociolinguists at Berkeley and the previous generation. Murray (1998: 131-3) points out that Hymes produced a rhetoric of continuity with the Sapirian and structuralist traditions in American linguistic anthropology, in part by including work by scholars such as Haas, Emeneau and Hockett in the anthology Language in Culture and Society (Hymes, 1964), and that the older and younger generations were always respectful of each other in their writing. This mutual respect, however, has historically occluded a very strong divide between their approaches to language. However much Hymes grounded his work in the past, he still demanded a break from prior linguistic study. Hymes advocated a shift in focus away from linguistic code 'la langue' to actual speech, 'la parole'. He argued for the primacy of language function, and for a shift from imagining the referential function of language as the primary one to seeing it as one of many. He saw the organizing principles of language as derived from language functions, and social appropriateness as essential criterion for the 'rightness' of utterances. He was fundamentally concerned with linguistic diversity, and so, perhaps most importantly, he demanded that language study be grounded in ethnographic observation rather than introspective theorizing.

In 1965, Hymes moved to the University of Pennsylvania, where he joined the faculty of the Department of Anthropology and trained what Murray (1998: 133) has called the 'second generation' of ethnographers of communication, whose work is represented in the influential anthology Explorations in the Ethnography of Communication co-edited by two of Hymes' students (Bauman and Sherzer, 1974). During this period, Hymes worked with other sociolinguists to create a new journal devoted to 'the means of speech in human communities, and their meanings to those who use them' (Hymes, 1972a: 2). The first issue of Language in Society appeared in 1972, published by Cambridge University Press, with Hymes as editor. At the University of Pennsylvania, Hymes was also affiliated with the Departments of Folklore and Folklife and Sociology, and with the faculty in education. Hymes became Dean of the 
University's College of Graduate Studies in Education in 1975. In 1987 he moved to the Department of Anthropology at the University of Virginia, from which he retired in 2000.

The generational shift from descriptive linguistics into sociolinguistics was contemporaneous with the Chomskyan shift to Transformational-Generative grammar. The sociolinguistics movement expressed continuity with prior generations of scholars, in contrast to the acrimony surrounding transformational grammarians' split with structural linguistics. But both represented fundamental changes in linguists' understanding of language. Hymes was particularly critical of Chomsky's idea of linguistic competence and his failure to account for linguistic variation. Locating language within an a priori mental grammar does not account for or even acknowledge the enormous role of the socially-contextualized ways we use language in determining the shape of utterances. We do more than construct grammatically possible linguistic utterances, and, as Hymes frequently noted, ungrammatical utterances may be socially appropriate, just as grammatical utterances can be socially inappropriate (Hymes, 1972b, 1989). Hymes objected to Chomsky's definition of linguistic competence in the strongest terms, saying that 'a child from whom any and all the grammatical sentences of a language might come with equal likelihood would be a social monster. Within the social matrix in which it acquires a system of grammar, a child acquires also a system of its use' (Hymes, 1974: 75). The system of use children acquire within a social matrix of language is 'communicative competence', Hymes' alternative to Chomsky's 'linguistic competence'. While, for Chomskyans, humans are born with the capacity for acquiring linguistic competence, communicative competence is learned and thus can be more or less complete or flexible. This shift in understanding competence reflects Hymes' concern for disadvantaged children who do not have equal access to the sociolinguistic resources they need (Hymes, 1971).

Hymes also took Chomsky to task for the failure of Transformational-Generative grammar to account for linguistic variation. Chomskyan linguistics focuses on the aspects of language that are uniform across speakers, ruling variation off the field of study by stipulating idealized speaker/hearers in completely homogeneous communities as its research object. Hymes is concerned with actual linguistic variety as found in speech and therefore calls for 'concepts and methods that enable us to deal with diversity ... [T] he great stumbling block is that the kinds of organization most developed by linguists presuppose the grammar as their frame of reference, [because they are concerned with the] analysis of a single, more or less homogenous, norm' (Hymes, 1989: 433). The concepts and methods for linguistic investigation that resulted from Hymes' concern with actual language use in social contexts would be 'the ethnography of communication'.

\section{The Ethnography of Communication}

Hymes is best known for his founding role in the ethnography of communication. Hymes

proposed the term 'ethnography of speaking', later amended to 'ethnography of communication', 
to describe a new approach to understanding language in use (Hymes, 1962, 1964). In doing this, Hymes aimed to move away from considering speech as an abstract model and toward investigating the diversity of speech as it is encountered in ethnographic fieldwork. Essentially, Hymes argues:

...that the study of language must concern itself with describing and analyzing the ability of the native speakers to use language for communication in real situations (communicative competence) rather than limiting itself to describing the potential ability of the ideal speaker/listener to produce grammatically correct sentences (linguistic competence). Speakers of a language in particular communities are able to communicate with each other in a manner which is not only correct but also appropriate to the sociocultural context. This ability involves a shared knowledge of the linguistic code as well as of the socio-cultural rules, norms and values which guide the conduct and interpretation of speech and other channels of communication in a community ... [T] he ethnography of communication ... is concerned with the questions of what a person knows about appropriate patterns of language use in his or her community and how he or she learns about it. (Farah, 1998: 125)

The object of study Hymes proposes for linguistics is 'ways of speaking' (Hymes 1989). The idea of language as a set of ways of speaking is an alternative to the idea of language as grammar, an abstracted set of rules or norms. Under the rubric of ways of speaking, Hymes offers a bipartite conception of speech that encompasses both the 'means of speech' available to speakers, and the 'speech economy' these speakers participate in. Thus Hymes offers a theoretical basis for language study that accounts for both linguistic variation from individual to individual and relative linguistic coherence across the social realm, while also offering a methodological heuristic for investigating communication, often represented in terms of the SPEAKING mnemonic.

This bipartite understanding of language is important because it equally foregrounds two aspects of speaking that Hymes feels cannot be separated: what speakers can and do say, and the communal context such speech occurs in. Speech does not occur in a vacuum, but rather within a specific context, and 'when the meaning of speech styles are analyzed, we realize that they entail dimensions of participant, setting, channel, and the like, which partly govern their meanings' (Hymes, 1989: 444). For Hymes, speech cannot be considered separate from the sociological and cultural factors that help shape linguistic form and create meaning, and so the frame he offers in place of grammar gives equal place to both aspects of speech: speech and the entailments that give meaning to speech cannot be considered in isolation. Hymes is thus adamant that any terminology adopted must treat both aspects of speech equally, discarding both 'speech styles and their contexts' and 'means of speech and their meanings' as being insufficient (446). Hymes points out that 'contexts' and 'meaning' fail to evoke 'the norms of interaction that go beyond 
choice and style, and the attitudes and beliefs that underlie both' as well as 'leav[ing] the focus on 'styles' and 'means', (446). The solution is to separate 'means of speech (comprising the features that enter into styles, as well as the styles themselves), and speech economy' (ibid.).

Hymes offers an explicit definition of means of speech as 'the features that enter into styles, as well as the styles themselves', but he does not do the same for economy of speech. Hymes does, however, talk about speech economy in such a way as to outline its major facets, and his choice of metaphor is instructive as well. Speech economy is a set of relationships within a speech community, the marketplace in which participants in speech use their means of speech, and those means of speech are in turn a constituent element of the speech economy. Means of speech and speech economy are conceptually distinct as elements of ways of speaking, but 'the two concepts are of course interrelated, even interdependent (as said, meanings lie in relationships), and from a thoroughgoing standpoint, the speech economy of a community includes its means of speech as one of the components that enter into its pattern of relationships' (ibid.).

As have other language theorists (Saussure, Austin, Bourdieu), Hymes uses an economic metaphor as part of his articulation of how speech works. In addition to using the word 'economy', Hymes also uses economic terms when he justifies his partitioning of ways of speaking into two parts as reflecting 'the major division of labor in our society between those who study verbal means and those who study conduct' (Hymes, 1989: 447, emphasis added). Hymes' economic analogy is useful: much as individuals use their means of production to produce goods and services, and then exchange these products in an economy, so too do speakers use their means of speech to produce discourse that is exchanged within a speech economy.

This idea of speakers acting in a speech economy accounts for the contextual, relational and socially-judged aspects of speech. By according speech economy equal status with means of speech, Hymes can frame utterances as being meaningless outside of a particular macro-social context and set of relationships, subject not just to decoding but also to aesthetic judgment from members of the speech economy. In this sense, ethnopoetics-culturally-relative aesthetic sensibility-enters into Hymes' conception of language. Hymes illustrates this through Stanley Newman's research on the Indian Yokuts language. Newman's research allowed him to construct grammatically-possible utterances that were, however, ineffective, either inadvertently humorous or pompous (ibid.). That is to say: within Yokuts means of speech were possible utterances that had no purchase in the Yokuts speech economy. This is the 'economic' aspect of speech, where the community makes judgments about how we may traffic in speech. As Hymes puts it, 'grammatical Yokuts is not what is possible to the grammar ... but what is possible according to Yokuts norms ... [W] have a normative definition of possible Yokuts that is best described as aesthetic or stylistic in nature' (448). This is communicative competence 
visible in a specific example_-grammar fails to account for rightness in Yokuts utterances, which hinge instead on context (the social) and aesthetics (ethnopoetics).

In addition to making visible the communally-judged aspect of speech, the idea of speech economy serves an important conceptual function in maintaining a balance between an understanding of language as communally shared and a way of accounting for individual choice and variation in speech. Hymes makes clear that he wants a reference frame beyond the abstracted norms of a grammar, and that 'we have reached a point at which the concept of grammar itself is that which needs to be transcended' (Hymes, 1989: 434). Hymes argues for an understanding of speech that includes the diversity of the particular, not just the structured norms of an abstraction. Ultimately, Hymes rejects an understanding of language where it is permissible 'to speak of the great role of language in general, but never language in particular; which leads to 'a tendency to treat some linguistic particularities as inferior' (Hymes 1989: 450). The idea of speech economy is significant in dealing with this tension between general models of language and language particularities because the metaphor of economy carries with it notions of the specific and general, the individual and the community. Conceptually, economy accounts for both individual actors and their aggregate conduct, and so the terms 'speech economy' and 'means of speech' maintain and make visible the tension between the particular speech of the individual and the aggregate speech economy. In this conception of ways of speaking, Hymes offers a theoretical basis for approaching language through the ethnography of communication.

Hymes proposes a general method of ethnographic investigation through taxonomic, descriptive fieldwork (Hymes, 1972b). He is careful to point out, however, that 'sociolinguistic fieldwork is not an end in itself', but rather 'a necessary part of the progress towards models (structural and generative) of sociolinguistic description, formulation of universal sets of features and relations, and explanatory theories' (1972b: 43). Hymes advocates comparative, ethnographic taxonomies as the only way to explore and understand language systematically, because 'communities differ significantly in the ways of speaking, in patterns of repertoire and switching, in the roles and meanings of speech. They indicate differences with regard to beliefs, values, reference groups, norms, and the like ... [I]ndividual accounts that individually pass without notice ... leap out when juxtaposed, as contrasts that require explanation' (1972b: 42). Descriptive and taxonomical ethnographic work that allows for comparison between speech communities allows for systemic classification of ways of speaking in four traditional areas: 'genetic classification' of language descent; 'areal classification' of features spread through an area; 'typological classification' of structural features independent of genetic or areal nature; and usage/role classification (i.e. as a pidgin, trade language, etc).

The sort of fieldwork Hymes advocates — ethnographies of communication-must 'discover and explicate the competence that enables members of a community to conduct and interpret speech' (Hymes, 1972b: 52). The exploration and documentation of communicative 
competence within a speech community is the essence of the ethnography of communication. As a means to this end, Hymes defines the social units and units of analysis for ethnographies of communication and proposes an etic heuristic for their analysis.

The social unit proper to sociolinguistics is the 'speech community'. By speech community, Hymes does not mean a community defined by common language, but rather by common linguistic norms: 'a community sharing rules for the conduct and interpretation of speech, and rules for the interpretation of at least one linguistic variety' (Hymes, 1972b: 54). This definition moves the ethnographer away from questions of grammar, and grammaticallypossible utterances, to questions of coherence and efficacy in the socially-situated use of language. The question for Hymes is not only whether speakers have a common understanding of syntax and semantics, but also whether or not they share ideas about the use of silence, ideas about the meaning of irony or emphasis, speech taboos, ways of formulating requests or statements, and so on.

Within speech communities, ethnographers must look for 'speech situations', 'speech events', and 'speech acts'. By speech situations, Hymes means socially-contextual situations like 'ceremonies, fights, hunts, meals, lovemaking, and the like' (Hymes, 1972b: 56). Speech events occur within speech situations, so for example the exchange of vows is a speech event occurring within a wedding (a speech situation). Speech acts are the individual utterances that form the minimal unit of analysis for ethnographies of communication. Hymes offers the example of 'a party (speech situation), a conversation during the party (speech event), a joke within the conversation (speech act)' to illustrate the three terms (ibid.). Hymes distinguishes speech acts from grammatical conceptions like sentences, because the meaning, status, and function of a speech act are not solely dependent upon grammatical form. The interpretation of speech acts is equally (at times more) dependent upon the social status and relationship of participants, as well as the immediate context of the utterance, and so 'the level of speech acts mediates immediately between the usual levels of grammar and the rest of a speech event or situation in that it implicates both linguistic form and social norms' (57).

To help ethnographers of communications frame their investigation of speech acts and events, Hymes offers the mnemonic device of the SPEAKING grid as a heuristic. Though it is by no means his most significant contribution to sociolinguistics, the SPEAKING grid is perhaps the artifact most associated with Hymes as his popular legacy. The SPEAKING grid has been widely accepted in the ethnography of communication, and has been further developed into discrete research questions by Hymes' students, Joel Sherzer and Regna Darnell (Sherzer and Darnell, 1972). The eight components of the SPEAKING mnemonic are:

(S) Setting including the time and place, physical aspects of the situation such as arrangement of furniture in the classroom; (P) participant identity including personal 
characteristics such as age and sex, social status, relationship with each other; (E) ends including the purpose of the event itself as well as the individual goals of the participants; (A) act, sequence or how speech acts are organized within a speech event and what topic/s are addressed; $(\mathrm{K})$ key or the tone and manner in which something is said or written; (I) instrumentalities or the linguistic code i.e. language, dialect, variety and channel i.e. speech or writing; $(\mathrm{N})$ norm or the standard socio-cultural rules of interaction and interpretation; and $(\mathrm{G})$ genre or type of event such as lecture, poem, letter. (Farah, 1998: 126)

Ultimately, this list of components of speech acts is meant to explore and explain human, social purposes in language. Like all taxonomies, the SPEAKING grid is not an end in itself, but rather a means: 'the formal analysis of speaking is a means to the understanding of human purposes and needs, and their satisfaction' (Hymes, 1972b: 70), as well as a way of understanding how language works.

The ethnography of communication is thus not just a method but a coherent theoretical approach to language. Hymes provides a theoretical basis for language in ways of speaking, which accounts for the diversity and efficacy of actual human communication in terms of the ideas of means of speech and speech economy. Hymes also offers a justification for ethnographic methods, because it is linguistic differences, the contrastive juxtaposition of different ways of speaking, which allows for classification and systematic analysis of language. In turn, Hymes offers a specific set of terminology ('speech community', 'situation', 'event' and 'act') and a suggested method for the conduct of the ethnography of communication (the SPEAKING mnemonic), with a specific unit of analysis in the speech act. Hymes has had an enormous impact in sociolinguistics by helping steer linguistic work toward human communication as it occurs in use: socially.

\section{Narrative and ethnopoetics}

As we have seen, Hymes's ethnography of communication provides both a theoretical basis and a methodological heuristic for exploring how language is embedded and enacted in discourse. Doing this kind of work requires paying attention to linguistic interaction in context. Ethnographers of communication explore the physical setting, the participants, their goals; the media and modes of communication; the norms that guide interpretation. In fact, sometimes the actual words are relatively unimportant. This concern for the whole of communication, instead of just grammatical form, has implications for Hymes in his study of American Indian languages.

Like many other US anthropological linguists, Hymes has always been a student of American Indian languages, and by the time he began his doctoral dissertation fieldwork in the 1950s, many of these languages were dying out. In the Pacific Northwest, Hymes's field site, Native American speech events could no longer be observed in their original contexts. Many of 
the Indians along the Columbia River had assimilated to European-American culture, moved, or died; if there were native speakers of some of the varieties of Chinook and Sahaptin spoken there, they were elderly and isolated, no longer part of a community of speakers. In some languages, Native American speech could no longer be recorded at all, since there were no longer any speakers of these languages. All that was available, in many cases, were versions of tales and myths that had been written down by earlier anthropologists, usually in ways that conformed to the anthropologists' expectations about how folk tales and myths should look on the page. They were inert, decontextualized, interesting in content but disconnected from the speech events that called them forth and shaped them, which could no longer be observed ethnographically.

Hymes's 'ethnopoetic' approach to this material was a theoretical framework and a set of methods for putting these tales and myths back into something like their original contexts. Like the literary theorists of his generation, Hymes believed in the value of close reading that is attentive to all the syntactic and semantic details of texts that constrain how readers can interpret texts' meaning. Following linguist Edward Sapir and literary theorist Kenneth Burke, with whom Hymes regularly corresponded (Jordan, 2005), Hymes saw language as a 'terministic screen' through which we see our world. Hymes also viewed narrative as a universal genre, centrally involved in the speech events in which culture is re-created and transmitted. By reading closely, Hymes proposed to reveal the implicit structure of traditional Indian narratives. This implicit structure would reveal much about how the narratives were embedded in and reflective of their cultural context. Particularly by looking at what happened when narrators 'broke through' into full performances, an analyst could see something of what made things coherent in the culture its aesthetic system, in other words, or its native ('ethno') poetics. Ethnopoetic work could both show the rest of the world what Native American verbal art was like and help recover lost knowledge about languages and cultures that had died out (Blommaert, 2006).

In Vain I Tried to Tell You: Essays in Native American Ethnopoetics (1981, 2nd edn. 2004) is a collection of Hymes's work in this area. Hymes sets out to show 'how appreciation and interpretation of performances as unique events can be united with analysis of the underlying rules and regularities which make performances possible and intelligible' (Hymes, 198: 79). (All references to In Vain I Tried to Tell You are to the 1981 University of Pennsylvania Press edition.) Hymes situates performance in the range of abilities that characterize cultural competence vis-à-vis behaviours: being able to interpret behaviour, being able to report on behaviour, and being able to repeat behaviour. For cultural insiders, these three types of knowledge are in an implicational relationship: people can interpret more behaviour than they can report and report less than they can repeat. In other words, we can sometimes understand what is going on in a situation without being able to say why, and we can talk about some culturally meaningful behaviours without being able to do them. Behaviour that can be repeated (a prayer, a dance step, a ritual) can be repeated simply as a way of reporting on its existence or commenting on it, or, at the other end of the axis, it can be performed, that is, done in such a 
way as to show that one means it and intends it to accomplish something. A person who is performing 'assumes responsibility to an audience' (Hymes, 1981: 84).

Finding truly performed speech is crucial for the analyst who wants to find evidence about culture in discourse, because 'performance is a mode of existence and realization that is partly constitutive of what the tradition is. The tradition itself exists partly for the sake of performance; performance is itself partly an end' (1981: 86). Hymes's discussion of the relation between performance and tradition draws on Roman Jakobson's (Jakobson, 1968, 1960) formulation of the functions utterances serve. For Jakobson, utterances always have multiple functions, though one or another can be the focus in a particular situation. Utterances can be more or less 'referential' (aimed at making a claim about the world), more or less 'conative' (aimed at getting an interlocutor to behave in a certain way), more or less 'expressive' (calling attention to the speaker), more or less 'metalingual' (about the language or other system in which they are encoded), and more or less 'phatic' (aimed at establishing contact among interlocutors). Most importantly for our purposes here, utterances can be more or less 'poetic', that is, more or less aimed at calling attention to patterns of similarity and difference in their own structure. Poetic utterances, in this sense (which is somewhat different from everyday uses of the term), are ones that make visible normally invisible, implied categories and relationships. They do this by juxtaposing co-members of a category in repeated structural or semantic patterns.

For Hymes, only fully-performed speech is fully poetic. The poetic features of performance, those that distinguish it from non-performed speech, are thus designed to put tradition (linguistic and cultural) on display, to present it rather than just to describe it. These features include iteration on various levels (repeated words, repeated structural patterns, repeated incidents in stories), quotation (which is another form of repetition), the repeated use of various initial particles roughly similar to the English word now, and the grouping of lines into sets with predictable numbers of lines in each. (In the Chinookan narratives Hymes studies, there are often sets of three and five.) Hymes's method for analyzing Native American texts is complex and not easy to systematize. 'In short', says Hymes:

a satisfactory solution emerges only after several tries. One plunges in media res, making trial segmentation by hand, and reconsiders and adjusts it in the light of the principles of consistent structure and form-meaning covariation. As one gets more deeply into a text, one gains a deeper sense of its inner logic and form, its particular integration of content and expression, and one's sense of inconsistency or arbitrariness of analysis grows firmer. (1981: 151)

Because ethnopoetic analysis as Hymes practices it is hard to teach or learn, Hymes's methods have not been taken up widely. However, the idea that language and culture emerge in performance (and that performance is thus a crucial site for sociolinguistic analysis) has 
continued to resonate among North American linguistic anthropologists. Hymes's student Richard Bauman (1977) first described linguistic and paralinguistic 'keys to performance' in relatively canonical, formal speech events like myth-telling. More recently, in keeping with theorists who talk about the ways in which all language is self-referential, Bauman and Charles Briggs (1990) broaden the notion of performance to include talk that is less 'fully performed', in Hymes's sense, but which still can be said to enact and recirculate culture. Another student, Joel Sherzer, has carried forward the idea that the language used in certain Native American speech events is best described in terms of lines, verses and stanzas (Sherzer, 1975, 1981).

The influence of Hymesian ethnopoetics is also evident in the work of Michael Silverstein (1985) and his students (e.g. Mannheim, 1986). In keeping with the field of sociolinguistics as a whole, the focus has shifted from monologic discourse to interaction, and from 'culture' as an abstraction to the processes by which people coordinate understandings of the world in real time. Silverstein, Asif Agha (2006), and others (e.g. Lempert, 2008) talk about 'interactional text' and about how patterns of repetition and variation (now called 'text metricality' rather than 'poetic structure') knit together interactants' words, gestures and prosody into an emergent set of meanings, personas and relationships.

\section{Voice and Educational Ethnography}

We have focused so far on the theoretical side of the ethnography of communication and ethnopoetics, and on Hymes's theoretical contributions to sociolinguistics as a whole. His work has always had applied goals as well, however, having to do with making unheard voices and ways of speaking hearable. This is particularly explicit in his work in ethnopoetics, and it is alluded to in the title of his collected essays in ethnopoetics: In Vain I Tried to Tell You. In the introduction to the volume, Hymes characterizes it as 'devoted to the first literature of North America' (1981: 5). He explains its title by saying:

If we refuse to consider and interpret the surprising facts of device, design, and performance inherent in the words of the texts, the Indians who made the texts, and those who preserved what they made, we will have worked in vain. We will be telling the texts not to speak. We will mistake, perhaps to our cost, the nature of the power of which they speak. (Hymes 1981: 5-6)

Hymes' work has always been linked with social activism, and the need for linguists to be able to integrate their 'scientific and social goals' (Hymes, 1996: 26) is the basis for one of his critiques of abstract, universalizing, asocial approaches to language.

The major themes in Dell Hymes' explicitly educational writings are the same as those in his work as a whole: the need for a view of language and linguistics broad enough that it has something to say and do about inequality, the significance and ubiquity of narrative poetics in the 
circulation of knowledge, and the importance of understanding linguistic behaviour in its ethnographic context. Hymes' contribution to educational sociolinguistics is centered in particular on the concept of 'narrative voice'.

The goal of Hymes's Native American ethnopoetics, as discussed above, was to reconstruct or 'salvage' the sociolinguistic and cultural frameworks in which Chinookan stories made sense, frameworks that were on the verge of disappearing. Only these frameworks made the texts Hymes studied fully and authentically interpretable; only these frameworks gave their tellers voice. By the same token, if not always for the same reasons, there are many children in the US and around the world who lack voice, children who cannot be heard because educators do not understand the frameworks in which their stories make sense. In his writing about language and education, Hymes hoped:

to show ... that aesthetic shape is normal, and probably universal, something that comes with language itself, ... that the possibility of narrative voice is given with the possibility of language, but at the same time, that its realization is partly at the mercy of others. (Hymes, 1996: xi)

Hymes' commitment to the application of sociolinguistic work in the world arises, arguably, out of his generally leftist, egalitarian, activist political stance (Blommaert, 2009). He positions himself against scholars who look for the universal in language and ignore the diversity among ways of speaking, because while diversity can be a resource, it can also be the basis for inequality.

In Speech and language: On the origins and foundations of inequality among speakers (Hymes, 1996: 25-62), based on a paper published in 1972, Hymes points out that linguistic diversity has always seemed problematic to Westerners, who have repeatedly proposed intellectual solutions involving original unity (from the Tower of Babel story to comparative searches for proto-languages to Universal Grammar) and practical solutions involving the privileging of a single language or variety. That diversity should pose a problem, however, or that original unity should be its solution, is not self-evident. For the Busama of New Guinea and the Quileute of Washington State, Hymes says, 'originally each person had a separate language, and ... community of language was a subsequent development' (Hymes, 1996: 28). What would a linguistics be like that took that view? Perhaps it would see, in the many languages and varieties that exist, evidence that social and historical adaptation is a stronger influence than shared roots or cognitive predisposition. Perhaps it would focus not on languages or dialects but on speech communities or ways of speaking.

Hymes also critiques other mainstream ideas about language: the idea that different linguistic channels (speaking, writing and signing) are simply different ways of encoding the same messages, the idea that language and reality are ideally in one-to-one correspondence, the 
idea that languages and varieties are thus potentially equivalent for practical purposes. In another essay, he argues that language study 'must overcome the separation between questions of language and questions of value that has characterized the development of modern linguistics in the United States' (Hymes, 1996: 100-1). The very adaptability of language implies maladaptation as well: resources suited to some purposes are unsuited to others. For linguists to continue to act as if the potential equality of languages (the fact that all are structurally complex, that lexica grow easily, that change is natural) were equivalent to actual equality is to sidestep some of the most important social issues to which linguistics is relevant. With Basil Bernstein, whose work Hymes takes seriously, he argues that while different ways of speaking may be equivalent from a linguistic perspective, '[s]ome discrimination among verbal abilities and products is not prejudice, but accurate judgment. The transformation of society to a juster, more equal way of life requires transformation of genuine equalities in verbal resource' (Hymes, 1996: 46).

Contra Bernstein, however, Hymes objects to binary divisions of styles into 'restricted' and 'elaborated' or, in Habermas' formulation of the nature of linguistic inequality, distorted communication versus the 'ideal speech situation'. While 'both Bernstein and Habermas are important in their pioneering efforts to analyze the problems of linguistic and communicative equality[,] both fall back on a cognitive ideal to which the absence of restriction, hence 'more is better', is intrinsic' (Hymes, 1996: 55; see also Ivinson, this volume). Since human life is always lived under cultural constraints, such theorists are unable to propose alternatives.

Hymes' proposal begins in arguing for narrative as a way of knowing. Because teaching and learning through stories has traditionally been devalued in American educational culture, in favour of 'rational' modes of information-processing, it is easy to fail to notice how the poetic patterning of traditional tales can help socialize children to see the world as patterned in certain ways, or to miss seeing that children's writing or oral storytelling is richly structured. In several essays Hymes proposes reanalyses, his or Virginia Hymes's, of other people's data, that uncover patterns of lines and stanzas. Hymes follows Roman Jakobson and is in line with most linguists in holding the assumption that makes decontextualized reanalyses of this sort possible: that structure inheres in texts, available for discovery to anyone who looks systematically. The fact that different analysts analyze texts differently suggests, though, that structuring may be an aspect of interpretation as well as an aspect of expression.

In talks and essays addressed to ethnographers of education, Hymes also talks about field methods. He reminds them that participant observation does not in itself constitute ethnography. He discusses what makes ethnography systematic and how it differs in fundamental epistemological ways from experimental research, ways that make it potentially empowering and democratizing. He compares the study of schools with ethnology, especially the study of Native 
American kinship, arguing that educational research should be more cumulative, more comparative, and more cooperative.

\section{Discussion}

Hymes' foundational works in sociolinguistics are still being read. They are included in collections of essential readings for anthropology and sociolinguistics (Duranti, 2009; Paulson and Tucker, 2003). His ethnopoetic work has also been recently republished (Hymes, 2003, 2004), and until recently, Hymes was still publishing in this area (Hymes, 2006). Although the concept of the speech community has been displaced to some degree by the community of practice (Lave and Wenger, 1991), it remains one of several possible analytical frameworks, more or less appropriate based on analytical purpose (Gee, 2005: 593; Holmes and Meyerhoff, 1999: 182).

Hymes is one of the most important figures in sociolinguistics: a founding member of the sociolinguistics movement, the originator of the ethnography of communication, a pioneer in ethnopoetics, and a champion in linguistics for those who have been unvoiced in Western educational, anthropological and linguistic traditions. It is in this last set of concerns, where Hymes was an advocate, doing truly applied linguistic work, that we can see the coherence in his work. The repeated theme of Hymes' scholarship is his insistence that linguistic theory and practice account for the individual, the particular and the actual. In countering Chomskyan linguistics, in proposing the ethnography of communication, and in his ethnopoetic approach to Native American texts, Hymes has always centred his theory and practice on what real human beings do with language. This insistence on the rich, socially-contextualized reality of human communication creates a particular affordance: the ability to apply sociolinguistic research to real-world problems of disadvantage and inequity. The ethnography of communication forces the sociolinguist to describe speech communities on their terms, sensitive to their norms of communication. Ethnopoetics forces readers to decentre themselves and interpret a text within its original context: the communication norms of the speech community that produced it. Hymes' work in voice and education has been marked by an insistence on meeting the unvoicedsocioeconomically disadvantaged children, American Indian speech communities within the larger US speech community - on their terms, within their context, and using their norms. Because Hymes resists the Western tendency to look only for the universal in language, he has been able to apply sociolinguistic research to the diverse, varied and local voices that have not received the ear they deserved. If we are sensitive to this coherency in Hymes work, the title of his ethnopoetics volume, In Vain I Tried to Tell You, takes on additional meaning. Hymes' significant contributions to sociolinguistics have helped make the discipline more aware of and accountable to multiple speech communities. 


\section{References}

Agha, A. (2006) Language and social relations. New York: Cambridge University Press.

Bauman, R. (1977) Verbal art as performance. Rowley, MA: Newbury House.

Bauman, R. and Briggs, C. (1990) 'Poetics and performance as critical perspectives on language and social life', Annual review of anthropology, 19: 59-88.

Bauman, R. and Sherzer, J. (eds) (1974) Explorations in the ethnography of communication. Cambridge: Cambridge University Press.

Blommaert, J. (2006) 'Ethnopoetics as functional reconstruction: Dell Hymes' narrative view of the world (Review article)', Functions of language, 13: 229-49.

Blommaert, J. (2009) 'Ethnography and democracy: Hymes' political theory of language', Text \& Talk, 29 (2).

Duranti, A. (2009) Linguistic Anthropology: A Reader. 2nd edn. Malden, MA: Blackwell.

Farah, I. (1998) 'The Ethnography of Communication', in N. H. Hornberger and P. Corson (eds) Encyclopedia of Language and Education: Volume 8: Research Methods in Language and Education. Dordrecht: Kluwer. pp. 125-7

Gee, J. (2005) 'Meaning making, communities of practice, and analytical toolkits', Journal of Sociolinguistics, 9 (4): 590-4.

Holmes, J. and Meyerhoff, M. (1999) 'The Community of Practice: Theories and methodologies in language and gender research', Language in Society, 28: 173-83.

Hymes, D. (n.d.). Dell H. Hymes Personal Web Page. Retrieved 16 January 2009, from http://www.virginia.edu/anthropology/dhymes.html.

Hymes, D. H. (ed.) (1971) Pidginization and Creolization of Languages: Proceedings of a Conference Held at the University of the West Indies, Mona, Jamaica, April.1968. Cambridge: Cambridge University Press.

Hymes, D. H. (ed.) (1964) Language in culture and society: A reader in linguistics and anthropology. New York: Harper \& Row. 
Hymes, D.H. (1972a) 'Editorial Introduction to "Language in Society"', Language in Society, 1 (1): $1-14$.

Hymes, D. H. (1972) 'Models of the interaction of language and social life', in J. J. Gumperz and D. Hymes (eds) Directions in sociolinguistics: The ethnography of communication. New York: Holt, Rinehart \& Winston. pp. 35-71.

Hymes, D. H. (1974) Foundations in sociolinguistics: An ethnographic approach. Philadephia: University of Pennsylvania Press.

Hymes, D. H. (1975) 'Pre-war Prague School and post-war American anthropological linguistics', in E. Koerner (ed.) The transformational-generative paradigm and modern linguistic theory. Amsterdam: John Benjamins. pp. 359-380.

Hymes, D. H. (1981) In vain I tried to tell you: Essays in Native American ethnopoetics. Philadelphia: University of Pennsylvania Press.

Hymes, D. H. (1989) 'Ways of speaking', in R. Bauman and J. Sherzer (eds) Explorations in the ethnography of speaking. 2nd edn. Cambridge: Cambridge University Press. pp. 433-51.

Hymes, D. H. (1996) Ethnography, Linguistics, Narrative Inequality: Toward An Understanding Of Voice. 1st edn. London:Taylor \& Francis.

Hymes, D. H. (2003) Now I Know Only So Far: Essays in Ethnopoetics. University of Nebraska Press.

Hymes, D. H. (2004) "In vain I tried to tell you": Essays in Native American Ethnopoetics. University of Nebraska Press.

Hymes, D. H. (2006) 'Ethnopoetics', Theory Culture Society, 23: 67-9.

Jakobson, R. (1960) 'Concluding statement: Linguistics and poetics', in T. Sebeok (ed.) Style in language. Cambridge, MA: MIT Press. pp. 350-77.

Jakobson, R. (1968) 'Poetry of grammar and grammar of poetry', Lingua, 21: 597-609.

Jordan, J. (2005) 'Dell Hymes, Kenneth Burke's "Identification," and the Birth of Sociolinguistics', Rhetoric review, 24: 264-79.

Lempert, M. (2008) 'The poetics of stance: Text-metricality, epistemicity, interaction', Language in Society, 37: 569-592. 
Mannheim, B. (1986) 'Popular song and popular grammar, poetry and metalanguage', Word, 37: 45-75.

Murray, S. O. (1998) American Sociolinguistics: Theorists and Theory Groups. Amsterdam/Philadelphia: John Benjamins Publishing Co.

Sherzer, J. (1975) 'Semantic systems, discourse structures, and the ecology of language', in R. W. Shuy (ed.) Studies in language variation. Washington, DC: Georgetown University Press. pp. 283-93.

Paulston, C. B. and Tucker, G. R. (2003) Sociolinguistics: The Essential Readings. Malden, MA: Blackwell.

Sherzer, J. (1981) 'The interplay of structure and function in Kuna narrative, or: How to grab a snake in the Darien', in Georgetown University Round Table on Languages and Linguistics, 1981. Washington D.C.: Georgetown University Press. pp. 306-322.

Sherzer, J. and Darnell, R. (1972) 'Outline field guide for the ethnographic study of speech use', in J. J. Gumperz and D. H. Hymes (eds) Directions in sociolinguistics: The ethnography of communication. New York: Holt, Rinehart, and Winston. pp. 548-54.

Silverstein, M. (1985) 'On the pragmatic 'poetry' of prose: Parallelism, repetition, and cohesive structure in the time course of dyadic conversation', in D. Schiffrin (ed.) Meaning, form, and use in context: Linguistic application. Georgetown University Round Table on Language and Linguistics. Washington, D.C.: Georgetown University Press. pp. 181-198. 